\title{
PENGARUH PENGGUNAAN MEDIA VIDEO PEMBELAJARAN TERHADAP PEMAHAMAN TENTANG KOIMUNIKASI DAN KONSELING OBAT PADA MAHASISWA S1 FARMASI
}

\author{
Influence of Use Video Learning Media on Understanding of Communications and Counseling \\ Medicine in Undergraduate Students Pharmacy
}

*Nurul Mardiati \& Ratna Restapaty

Department of Pharmacy, Sekolah Tinggi Ilmu Kesehatan Borneo Lestari, Kelapa Sawit $8^{\text {th }}$ Bumi Berkat St. No. I Banjar Baru, Indonesia

*e-mail : nurulmardiati2007@gmail.com

\begin{abstract}
ABSTRAK
Dalam kegiatan belajar mengajar diharapkan dosen bisa menggunakan media pembelajaran yang kreatif dengan penggunaan media yang tepat agar konsep-konsep yang akan disampaikan dapat mencapai tujuan pendidikan yang diinginkan. Media pembelajaran merupakan suatu alat bantu yang digunakan oleh dosen untuk memudahkan penyampaian materi pembelajaran. Media pembelajaran yang dapat digunakan sangat bervariasi, salah satunya adalah video pembelajaran. Penelitian ini bertujuan untuk mengetahui pengaruh penggunaan media video pembelajaran terhadap pemahaman tentang komunikasi dan konseling obat pada mahasiswa SI Farmasi Sekolah Tinggi IImu Kesehatan Borneo Lestari Semester V Tahun Ajaran 2016/2017. Penelitian ini menggunakan metode eksperimen. Desain penelitian digunakan adalah The Randommized Control-Group Pretest-Posttest Control Group Design. Dalam desain ini terdapat dua kelompok yang terlebih dahulu dipilih secara random satu kelas untuk kelompok eksperimen (menggunakan video pembelajaran) dan satu kelas untuk kelompok kontrol (tidak menggunakan media video pembelajaran). Nilai sign berdasarkan uji wilcoxon menunjukkan 0,025<0,05 menunjukkan bahwasanya ada pengaruh penggunaan media video pembelajaran terhadap pemahaman tentang komunikasi dan konseling obat pada mahasiswa SI Farmasi Sekolah Tinggi Ilmu Kesehatan Borneo Lestari Semester V Tahun Ajaran 2016/2017.
\end{abstract}

Kata kunci: Media pembelajaran, video pembelajaran, komunikasi, konseling obat

\section{ABSTRACT}

Teaching learning activities by lecturers are expected can use creative learning media with the use of appropriate media for the concepts to be conveyed to achieve the desired educational goals. Learning media is a tool used by lecturers to facilitate the delivery of learning materials. Learning media that can be used alone vary widely, one of which is learning video. This study aims to determine the influence of the use of video learning media on understanding of communication and counseling drug on undergraduate students Pharmacy High School of Health Sciences Borneo Lestari Semester V Academic Year 2016/2017. This research is using experimental method. The research design used was The Randomized Control-Group Pretest-Posttest Control Group Design. In this design there are two groups that first randomly selected one class for the experimental group (using learning video) and one class for the control group (not using instructional video media). Sign value based on Wilcoxon test shows $0,025<0,05$. This indicates that there is the influence of $t$ use of video learning media on understanding of communication and counseling drug on undergraduate students Pharmacy High School of Health Sciences Borneo Lestari Semester V Academic Year 2016/2017.

Keywords: Learning media, video learning, communication, drug counseling

\section{PENDAHULUAN}

Kemampuan mengembangkan wawasan dan keterampilan calon tenaga kefarmasian dalam melakukan pekerjaan kefarmasian diperoleh melalui proses pembelajaran di perguruan tinggi. Perguruan Tinggi bermutu menjadi tuntutan mutlak yang harus dipenuhi oleh penyelenggara pendidikan, salah satunya dengan menghasilkan lulusan yang berkompeten yang mampu bersaing dalam dunia kerja. Kompetensi lulusan dapat dicapai melalui dengan menerapkan metode pembelajaran yang bervariasi. Dosen harus dapat melakukan pembelajaran yang inovatif dan kreatif sehingga pembelajaran akan berkualitas dalam proses dan hasilnya. Dalam kegiatan belajar mengajar diharapkan dosen bisa menggunakan media pembelajaran yang kreatif dengan penggunaan media yang tepat agar konsep-konsep yang akan disampaikan dapat mencapai tujuan pendidikan yang diinginkan.

Kata media merupakan bentuk jamak dari kata medium. Medium dapat didefinisikan sebagai perantara atau pengantar terjadinya komunikasi dari pengirim menuju (Daryanto,2010). Dalam bahasa Arab, media adalah perantara atau pengantar pesan dari pengirim kepada penerima pesan (Arsyad, 2007). 
Sedangkan pengertian media secara terminologi cukup beragam, sesuai sudut pandang para media pendidikan. Menurut Cecep dan Bambang (20II) media merupakan perantara atau pengantar pesan dari pengirim ke penerima pesan. Media merupakan wadah dari pesan yang oleh sumbernya ingin diteruskan kepada sasaran atau penerima pesan tersebut. Media merupakan salah satu komponen komunikasi yaitu sebagai pembawa pesan dari komunikator menuju komunikan (Daryanto, 2010). Media pembelajaran pada prinsipnya merupakan suatu alat bantu yang digunakan oleh dosen untuk memudahkan penyampaian materi pembelajaran. Media pembelajaran yang dapat digunakan sendiri sangat bervariasi, salah satunya adalah video pembelajaran.

Penggunaan video dinilai dapat memberikan pengalaman baru terhadap mahasiswa. Menurut Daryanto (2010) media video merupakan segala hal yang memungkinkan sinyal audio dapat dikombinasikan dengan gambar bergerak secara sekuensial. Lebih jauh, video juga dinyatakan sebagai medium yang sangat efektif untuk membantu proses pembelajaran, baik untuk pembelajaran massal, individual, maupun kelompok. Penelitian ini bertujuan untuk mengetahui pengaruh penggunaan media video pembelajaran terhadap pemahaman tentang komunikasi dan konseling obat pada mahasiswa SI Farmasi Sekolah Tinggi Ilmu Kesehatan Borneo Lestari Semester V Tahun Ajaran 2016/2017.

\section{METODOLOGI}

\section{Subjek Penelitian}

Subyek penelitian ini adalah mahasiswa SI Farmasi Sekolah Tinggi Ilmu Kesehatan Borneo Lestari Semester V Tahun Ajaran 2016/2017 dengan jumlah sampel 80 mahasiswa yang terbagi dalam dua kelompok yaitu 40 mahasiswa kelompok eksperimen dan 40 mahasiswa kelompok kontrol yang ditentukan secara random.

\section{Instrumen Penelitian}

Instrumen penelitian ini digunakan untuk mengukur tingkat pemahaman tentang komunikasi dan konseling obat. Instrumen untuk mengukur pemahaman berupa kuesioner dalam bentuk soal terstruktur yang terdiri dari 30 pertanyaan multiple choice. Pengukuran tingkat pemahaman mahasiswa memuat indikator komunikasi verbal; komunikasi nonverbal; faktor penunjang dalam komunikasi; komunikasi interpersonal; strategi komunikasi interpersonal (keterbukaan, empati, dukungan, rasa positif, dan kesamaan); etika dan norma komunikasi; rekomendasi obat yang independen, akurat, komprehensif; konseling rawat jalan; dan pendekatan dalam meningkatkan kepatuhan.

\section{Desain Penelitian}

Penelitian ini menggunakan metode eksperimen. Desain penelitian digunakan adalah The Randomized Control-Group Pretest-Posttest Control Group Design. Dalam desain ini terdapat dua kelompok yang terlebih dahulu dipilih secara random satu kelas untuk kelompok eksperimen (menggunakan video pembelajaran) dan satu kelas untuk kelompok kontrol (tidak menggunakan media video pembelajaran). Selanjutnya kedua kelompok mahasiswa ini diberi tes awal atau pre test. Pemberian pre test dilakukan untuk memperoleh data awal tentang pemahaman mahasiswa tentang komunikasi dan konseling obat.

Setelah dilakukan pre test kemudian diberikan post test. Pemberian tes ini dilakukan setelah mahasiswa melewati proses pembelajaran dengan jumlah masing-masing 14 kali pertemuan. Kelompok kontrol dan eksperimen menggunakan Rencana Pembelajaran Semester (RPS) dan metode yang sama yaitu metode ceramah dan diskusi kelompok, namun pada kelompok eksperimen ditambahkan dengan media video pembelajaran yang memuat dari kutipan-kutipan teori tentang komunikasi dan konseling serta role playing adegan dilakukannya konseling obat apoteker ke pasien.

\section{Analisis Data}

Analisis data yang dilakukan dalam penelitian ini meliputi analisis deskripstif. Tingkat pemahaman mahasiswa digolongkan berdasarkan skor jawaban mahasiswa. Kategorisasi tingkat pemahaman mahasiswa dikelompokkan menjadi tuntas dengan kategori skor $<70$ dan tidak tuntas dengan kategori skor $\geq 70$. Sedangkan untuk mengetahui ada tidaknya pengaruh penggunaan media video pembelajaran terhadap pemahaman tentang komunikasi dan konseling obat pada mahasiswa SI Farmasi Sekolah Tinggi Ilmu Kesehatan Borneo Lestari Semester V Tahun Ajaran 2016/2017 dilakukan dengan uji sign test/Wilcoxon. Jika nilai signifikansi $<0,05$ maka $\mathrm{HO}$ di tolak artinya ada pengaruh antar variabel yang diuji, jika nilai signifikansi > 0,05 maka $\mathrm{HO}$ di terima artinya tidak ada pengaruh antar variabel yang diuji.

\section{HASIL DAN PEMBAHASAN}

Hasil pre-test kelompok eksperimen disajikan pada Tabel I. Berdasarkan Tabel I. diketahui bahwasanya mayoritas mahasiswa pada kelompok eksperimen yaitu 38 orang (95\%) telah mencapai ketuntasan dalam memahami konsep komunikasi dan konseling obat. Sedangkan sisanya 2 orang 
(5\%) belum mencapai ketuntasan dalam memahami konsep komunikasi dan konseling obat.

Tabel I. Hasil Pre-test Kelompok Eksperimen

\begin{tabular}{cccc}
\hline Kategori & Nilai & $\begin{array}{c}\text { Jumlah Mahasiswa } \\
\text { (orang) }\end{array}$ & $\begin{array}{c}\text { Persentase } \\
\text { (\%) }\end{array}$ \\
\hline Tuntas & $\geq 70$ & 2 & 5 \\
Belum Tuntas & $<70$ & 38 & 95 \\
\hline
\end{tabular}

Hasil pre-test kelompok eksperimen disajikan pada Tabel II. Hasil pre-test kelompok kontrol menunjukkan hasil yang hampir sama dengan kelompok eksperimen. Berdasarkan Tabel II diketahui bahwasanya seluruh mahasiswa yaitu 40 orang (100\%) telah mencapai ketuntasan dalam memahami konsep komunikasi dan konseling obat.

Tabel II. Hasil Pre-test Kelompok Kontrol

\begin{tabular}{cccc}
\hline Kategori & Nilai & $\begin{array}{c}\text { Jumlah Mahasiswa } \\
\text { (orang) }\end{array}$ & $\begin{array}{c}\text { Persentase } \\
\text { (\%) }\end{array}$ \\
\hline Tuntas & $\geq 70$ & 0 & 0 \\
Belum Tuntas & $<70$ & 40 & 100 \\
\hline
\end{tabular}

Hasil post-test kelompok eksperimen disajikan pada Tabel III. Berdasarkan Tabel III. diketahui bahwa mayoritas mahasiswa pada kelompok eksperimen yaitu 24 orang (60\%) telah mencapai ketuntasan dalam memahami konsep komunikasi dan konseling obat. Sedangkan sisanya 16 orang (40\%) masih belum mencapai ketuntasan dalam memahami konsep komunikasi dan konseling obat.

Tabel III. Hasil Post-test Kelompok Eksperimen

\begin{tabular}{cccc}
\hline Kategori & Nilai & $\begin{array}{c}\text { Jumlah Mahasiswa } \\
\text { (orang) }\end{array}$ & $\begin{array}{c}\text { Persentase } \\
\text { (\%) }\end{array}$ \\
\hline Tuntas & $\geq 70$ & 16 & 40 \\
Belum Tuntas & $<70$ & 24 & 60 \\
\hline
\end{tabular}

Hasil post-test kelompok eksperimen disajikan pada Tabel IV. Hasil post-test kelompok kontrol pada Tabel IV. menunjukkan bahwasanya mayoritas mahasiswa yaitu 36 orang $(90 \%)$ telah mencapai ketuntasan dalam memahami konsep komunikasi dan konseling obat. Sedangkan sisanya 4 orang (10\%) masih belum mencapai ketuntasan dalam memahami konsep komunikasi dan konseling obat.

Tabel IV. Hasil Post-test Kelompok Kontrol

\begin{tabular}{cccc}
\hline Kategori & Nilai & $\begin{array}{c}\text { Jumlah Mahasiswa } \\
\text { (orang) }\end{array}$ & $\begin{array}{c}\text { Persentase } \\
\text { (\%) }\end{array}$ \\
\hline Tuntas & $\geq 70$ & 4 & 10 \\
Belum Tuntas & $<70$ & 36 & 90 \\
\hline
\end{tabular}

Berdasarkan Tabel III dan IV tergambar bahwasanya jumlah mahasiswa yang mencapai ketuntasan dalam memahami konsep komunikasi dan konseling obat pada kelompok eksperimen lebih besar dibandingkan jumlah mahasiswa pada kelompok kontrol. Konsistensi data juga tergambar dari jumlah mahasiswa yang belum mencapai ketuntasan dalam memahami konsep komunikasi dan konseling obat pada kelompok eksperimen yang lebih kecil jika dibandingkan dengan kelompok kontrol.

Hasil uji sign test kelompok eksperimen disajikan pada Tabel V. Hasil output frequencies uji sign test menunjukkan bahawasanya jumlah selisih antara pretest dan posttest sejumlah 12 mahasiswa berselisih negatif, 27 mahasiswa yang berselisih positif, dan I mahasiswa yang memiliki selisih yang sama.

Tabel V. Hasil Uji Sign Test Kelompok Eksperimen

\begin{tabular}{lc}
\multicolumn{1}{c}{ Frequencies } & N \\
\hline Post- Pre Negatif Differences $^{a}$ & 12 \\
Positive Differences $^{b}$ & 27 \\
Ties $^{c}$ & I \\
\hline Total & 40 \\
\hline a. Post $<$ Pre & \\
b. Post $>$ Pre & \\
c. Post $=$ Pre &
\end{tabular}

Hasil uji wilcoxon kelompok eksperimen disajikan pada Tabel VI. Nilai sign berdasarkan uji wilcoxon menunjukkan $0,025<0,05$. Hal ini menunjukkan bahwasanya ada pengaruh penggunaan media video pembelajaran terhadap pemahaman tentang komunikasi dan konseling obat pada mahasiswa SI Farmasi Sekolah Tinggi Ilmu Kesehatan Borneo Lestari Semester V Tahun Ajaran 2016/2017. Hal ini sesuai dengan hasil penelitian oleh Irawan (2015) dan Wirdana (2016).

Tabel VI. Hasil uji wilcoxon kelompok eksperimen

\begin{tabular}{lc}
\multicolumn{1}{c}{ Test Statistica } & Post-Pre \\
\hline $\mathrm{Z}$ & $-2,242$ \\
Asymp/Sig. (2-tailed) & 0,025 \\
\hline$a . \quad$ Wilcoxon test
\end{tabular}

Daryanto (2010) menyatakan bahwasanya tingkat retensi peserta didik terhadap materi pembelajaran dapat meningkat secara signifikan jika proses pemerolehan informasi awalnya lebih besar melalui indera pendengaran dan penglihatan, dalam hal ini video pembelajaran. Media video dapat menarik perhatian peserta didik dan menumbuhkan motivasi mahasiswa dalam mengikuti kegiatan pembelajaran sehingga meningkatkan pemahaman. Menurut Sadiman(20I I) kelebihan media video antara lain, a) dapat menarik perhatian untuk periode-periodeyang singkat dari rangsangan luar lainnya b)dengan alat perekam pita video sejumlah besar penonton dapat memperoleh informasi dari ahli-ahli atau spesialis c)menghemat waktu dan rekaman dapat diputar berulang-ulang d)kamera TV bisa mengamati lebih dekat objek yang sedang bergerak atau objek yang berbahaya e)keras lemah suara yang ada bisa diatur dan disesuaikan bila akan disisipi komentar yang akan di dengar f) gambar proyeksi biasa “dibekukan" untuk diamati dengan seksama g)ruangan tidak perlu digelapkan waktu penyajiannya. Meskipun memiliki beberapa 
kelebihan, media video juga memiliki beberapa kelemahan, antara lain, a) perhatian penonton sulit dikuasai, partisipasi jarang dipraktikkan; b) sifat komunikasinya berkomunikasinya bersifat satu arah dan harus diimbangi dengan pencarian bentuk umpan balik yang lain; c) kurang mampu menampilkan detail dari objek yang disajikan secara sempurna; d) memerlukan peralatan yang mahal dan kompleks.

\section{KESIMPULAN}

Ada pengaruh penggunaan media video pembelajaran terhadap pemahaman tentang komunikasi dan konseling obat pada mahasiswa SI Farmasi Sekolah Tinggi Ilmu Kesehatan Borneo Lestari Semester V Tahun Ajaran 2016/2017. Saran yang dapat diberikan berdasarkan penelitian yang telah dilakukan yaitu penggunaan media video pembelajaran dapat menjadi salah satu alternatif dalam meningkatkan pemahaman tentang mahasiswa tentang komunikasi dan konseling obat, khususnya dalam mata kuliah Komunikasi, Informasi dan Edukasi.

\section{DAFTAR PUSTAKA}

Arsyad, A. 2007. Media Pengajaran. Jakarta, PT Raja Grafindo Persada.

Cecep dan Bambang. 2011. Media Pembelajaran. Bogor, Ghalia Indonesia.

Daryanto. 20I0. Media Pembelajaran. Yogyakarta, Gava Media.

Irawan, R.K. 2015. Pengaruh Penggunaan Media Video terhadap Hasil Belajar IPA Siswa Kelas IV SDN Pajang III No.206 Surakarta Tahun 20I4/20I5. Skripsi, Universitas Muhammadiyah Surakarta.

Sadiman, A.S. 201I. Media Pendidikan Pengertian, Pengembangan, dan Pemanfaatannya. Jakarta, Rajawali Pers.

Wirdana. 2016. Pengaruh Video Pembelajaran terhadap Hasil Belajar IPA Siswa Kelas V di SDN Inti Tondo Palu. Skripsi, UniversitasTadulako. 